\section{OPEN ACCESS}

Edited by:

Andries Kalsbeek

Academic Medical Center,

Netherlands

Reviewed by:

Virginie Tolle,

French Institute of Health and Medical

Research (INSERM), France

Carolina Escobar,

Universidad Nacional Autónoma de

México (UNAM), Mexico

*Correspondence:

Margaret De Castro castrom@fmrp.usp.br

Specialty section:

This article was submitted to Neuroendocrine Science, a section of the journal

Frontiers in Neuroscience

Received: 22 August 2016 Accepted: 24 November 2016 Published: 07 December 2016

Citation:

De Araujo LD, Roa SL, Bueno AC, Coeli-Lacchini FB, Martins CS, Uchoa ET, Antunes-Rodrigues J,

Elias $L L$, Elias $P C$, Moreira $A C$ and De Castro M (2016) Restricted Feeding Schedules Modulate in a Different Manner the Expression of Clock Genes in Rat Hypothalamic Nuclei. Front. Neurosci. 10:567. doi: 10.3389/fnins.2016.00567

\title{
Restricted Feeding Schedules Modulate in a Different Manner the Expression of Clock Genes in Rat Hypothalamic Nuclei
}

\begin{abstract}
Leonardo D. De Araujo ${ }^{1}$, Silvia L. Roa ${ }^{2}$, Ana C. Bueno ${ }^{3}$, Fernanda B. Coeli-Lacchini ${ }^{2}$, Clarissa S. Martins ${ }^{2}$, Ernane T. Uchoa ${ }^{1}$, Jose Antunes-Rodrigues ${ }^{1}$, Lucila L. Elias ${ }^{1}$, Paula C. Elias ${ }^{2}$, Ayrton C. Moreira ${ }^{2}$ and Margaret De Castro ${ }^{2 *}$
\end{abstract}

${ }^{1}$ Department of Physiology, University of Sao Paulo, Ribeirao Preto, Brazil, ${ }^{2}$ Department of Internal Medicine, University of Sao Paulo, Ribeirao Preto, Brazil, ${ }^{3}$ Department of Pediatrics of the Ribeirao Preto Medical School, University of Sao Paulo, Ribeirao Preto, Brazil

Food access restriction is associated to changes in gene expression of the circadian clock system. However, there are only a few studies investigating the effects of non-photic synchronizers, such as food entrainment, on the expression of clock genes in the central oscillators. We hypothesized that different feeding restriction patterns could modulate the expression of clock genes in the suprachiasmatic nucleus (SCN) "master" clock and in extra-SCN oscillators such as the paraventricular (PVN) and arcuate (ARC) hypothalamic nuclei. Wistar rats were divided into four groups: Control group (CG; food available ad libitum), Restricted night-fed (RF-n; food access during $2 \mathrm{~h}$ at night), Restricted day-fed (RF-d; food access during $2 \mathrm{~h}$ at daytime), Day-fed (DF; food access during $12 \mathrm{~h}$ at daytime). After 21 days, rats were decapitated between ZT2-ZT3 (0800-0900 h); ZT11-ZT12 (1700-1800 h), or ZT17-18 (2300-2400 h). Plasma corticosterone was measured by radioimmunoassay (RIA). The expression of Clock, Bmal1, Per1, Per2, Per3, Cry1, Cry2, Rev-erb $\alpha$, and Ror $\alpha$ were assessed in SCN, PVN, and ARC hypothalamic nuclei by RT-PCR and calculated by the $2^{[- \text {DeltaDeltaCT(Cyclethreshold)] }}\left(2^{-\Delta \Delta C T}\right)$ method. Restricted food availability during few $\mathrm{h}$ led to decreased body weight in RF-n and RF-d groups compared to controls and DF group. We also observed an anticipatory corticosterone peak before food availability in RF-n and RF-d groups. Furthermore, the pattern of clock gene expression in response to RF-n, RF-d, and DF schedules was affected differently in the SCN, PVN, and ARC hypothalamic nuclei. In conclusion, the master oscillator in SCN as well as the oscillator in PVN and ARC, all brain areas involved in food intake, responds in a tissue-specific manner to feeding restriction.

\section{Keywords: circadian oscillators, hypothalamic nuclei, food restriction, clock gene expression, corticosterone}

\section{INTRODUCTION}

Physiological rhythms are regulated by neuronal hypothalamic circadian oscillators (Bass and Takahashi, 2010). Circadian oscillators are kept synchronized one with another and with environmental time by the suprachiasmatic nucleus (SCN), known as "master" clock in mammals. The SCN receives direct photic input from the retina, generates a pronounced circadian rhythm and in turn, synchronizes other subsidiary cellular oscillators (Reppert and Weaver, 2001). 
In mammals, the mechanism of cell-autonomous circadian clock depends on two core clock genes, Clock, and Bmal1, which are transcriptional activators of an auto-regulatory negative feedback loop (Lowrey and Takahashi, 2004). These genes form a heterodimer that activates their target genes, Period (Per), and Cryptochrome (Cry), which form a repressor complex in the cytoplasm that returns to the nucleus and interacts with CLOCKBMAL1 to inhibit their own transcription (Takahashi et al., 2008). Bmall and Clock genes also increase the mRNA levels of Rev-erb $\alpha$ and Ror $\alpha$, which compete for the binding to the retinoic acidrelated orphan receptor response elements (ROREs) repressing or activating the expression of Bmal1 (Green et al., 2008). Posttranslational modifications also modulate these auto-regulatory loops (Lamia et al., 2009; Nakahata et al., 2009; Jang et al., 2012).

Glucocorticoid circadian secretion is modulated via $\mathrm{CRH}$ and ACTH periodic release under the SCN control (Dallman et al., 1978, 1993; Buijs et al., 2003; Fahrenkrug et al., 2008). Furthermore, the glucocorticoid release is also modulated by the central circadian clock system in a manner independent of the HPA axis, possibly due to altering the sensitivity of the adrenal cortex to ACTH through the autonomic nervous system (Ishida et al., 2005; Kalsbeek et al., 2006; Nader et al., 2010). In addition to the photoperiod, feeding time is a powerful Zeitgeber of the glucocorticoid circadian rhythm. Rats display an anticipatory peak of glucocorticoid, release $1-2 \mathrm{~h}$ before the availability of food (Krieger et al., 1977). This phenomenon seems to be dependent on a distinct food-entrainable hypothalamic oscillator (Stephan et al., 1979; Stephan, 2002). Indeed, glucocorticoids are required for meal-induced changes in the expression of hypothalamic neuropeptides (Uchoa et al., 2012). Paraventricular (PVN) and arcuate (ARC) nuclei have been implicated in the control of energy homeostasis and express orexigenic and anorexigenic peptides. PVN receives projections not only from satiety-related neurons from the nucleus of the solitary tract but also from ARC neurons indicating that the hypothalamus plays an important role in the integrative responses that control food intake (Schwartz et al., 2000).

Although SCN generates a circadian rhythm, the daily rhythm of food intake can also regulate other hypothalamic nuclei, such as PVN, ARC, dorsomedial (DMH), and ventromedial (VMH) nuclei. Previous studies tested the susceptibility of nonphotic entrainment cues and demonstrated that restricting food availability with maintenance of photoperiod cues, is a strong Zeitgeber that changes only slightly SCN clock gene expression but can alter Per1, Per2, and Bmal1 expression in the PVN, anterior pituitary, and adrenal tissue (Girotti et al., 2009). In addition, timed hypocaloric feeding was also able to synchronize the temporal organization of SCN clockwork (Caldelas et al., 2005). Moreover, restricted feeding schedules entrain oscillations of Per1, Per2, and Bmal1 expression in different phases among various hypothalamic structures (Mieda et al., 2006; Verwey et al., 2007; Minana-Solis et al., 2009). Furthermore, peripheral clocks, particularly the liver, pancreas, kidney, and heart can be modulated by food restriction (Damiola et al., 2000; Le Minh et al., 2001; Stokkan et al., 2001; Green et al., 2008).

The majority of the studies on the effects of non-photic synchronizers, such as food entrainment, on the expression of clock genes in the hypothalamus used restriction feeding schedule with access to food restricted to a few hours daily during the light phase. In nocturnal animals, restricting feeding time to the dark does not seem to significantly alter the phase angle of the cyclic clock gene expression (Damiola et al., 2000). However, when food is offered only during the light phase, the expression of clock-related genes in the liver becomes inverted (Damiola et al., 2000; Le Minh et al., 2001). Moreover, food restriction, i.e., hypocaloric feeding, seems to cause changes not only in the temporal organization of peripheral oscillators, but also in the circadian SCN rhythm in rodents (Challet, 2007). Therefore, in this study, we investigate whether different restricted feeding schedules during the light phase or during the dark phase can alter clock gene expression in the SCN and other hypothalamic nuclei of rats despite the presence of photoperiodic cues.

\section{MATERIALS AND METHODS}

\section{Animals and Experimental Design}

This study was approved by the Animal Ethics Committee of the Ribeirao Preto Medical School of University of Sao Paulo, Brazil (Protocol $n^{\circ}$ 077/2011). Adult male Wistar rats weighing about $200 \mathrm{~g}$, were housed for 5 days in individual cages with food and water ad libitum, under controlled conditions of temperature, humidity and on a 12:12 h light/dark (LD) cycle, with lights on at $0600 \mathrm{~h}$ (Zeitgeber time; ZT 0).

All animals were fed with standard chow. After 5 days of acclimation period, rats were divided into four groups with different dietary patterns for 21 days. Control group (CG, total number of 23 rats): food ad libitum, available at all the time; Restricted night-fed (RF-n, total number of 25 rats): access to food restricted to ZT12-ZT14 (1800-2000 h); Restricted dayfed (RF-d, total number of 27 rats): access to food restricted to ZT3-ZT5 (0900-1100 h); Day-fed (DF, total number of 21 rats): access to food from ZT0-ZT12 (0600-1800 h). Water was offered ad libitum to all groups. Food intake and body weight were determined every day throughout the experiment. On the 21th day, 6-10 rats were decapitated per time point between 0800 and $0900 \mathrm{~h}$ (ZT3), between 1700 and $1800 \mathrm{~h}$ (ZT11), or between 2300 and $2400 \mathrm{~h}$ (ZT17).

To avoid unspecific or stress-related elevations of corticosterone secretion, animals were handled by the same investigator during the experiment and on the last day animals were decapitated within $60 \mathrm{~s}$. Trunk blood was immediately collected for corticosterone determination by RIA, as previously described (Castro et al., 1995). The assay sensitivity was $0.4 \mu \mathrm{g} / \mathrm{dl}$, and the inter- and intra-assay variations were $4.8 \%$ and $6.7 \%$, respectively. Animals of control group decapitated at ZT3, which showed plasma concentrations of corticosterone above $3 \mathrm{ug} / \mathrm{dl}$ were excluded because of undesirable stress condition, as previously published by our laboratory (Laguna-Abreu et al., 2005).

Brain was collected and flash-frozen in a dry ice-isopentene bath at $-30^{\circ} \mathrm{C}$ and stored at $-80^{\circ} \mathrm{C}$ until processing. SCN, PVN, and ARC hypothalamic nuclei were microdissected bilaterally by punch technique in a cryostat according to coordinates from -0.92 to -1.52 (600 $\mu \mathrm{m}$ thicknesses), -0.92 to $-2.12(1200 \mu \mathrm{m})$, 
-2.12 to $-3.62(1500 \mu \mathrm{m})$ from the bregma (Paxinos, 1997), respectively, using a stainless steel punch needle of $1.0 \mathrm{~mm}$ in diameter for the SCN and $1.5 \mathrm{~mm}$ for other nuclei. Tissue samples were transferred to a microtube containing RNA later reagent (Ambion, USA) and stored at $-80^{\circ} \mathrm{C}$ until RNA isolation.

\section{RNA Isolation, cDNA Synthesis, and Amplification by Real-Time PCR}

Total RNA was isolated from each micropunched hypothalamic tissue sample using TRIzol reagent (Life Technologies) according to the manufacturer's protocol. RNA concentrations were quantified by spectrometry (Nanodrop 2000, Thermo Fisher Scientific Inc., Waltham, MA, USA). RNA integrity was verified by measuring the $28 / 18 \mathrm{~S}$ ratio, with an acceptable range of 1.62.0 and confirmed by $1.2 \%$ agarose gel electrophoresis. mRNA was reverse transcribed from $500 \mathrm{ng}$ of total RNA using the High Capacity cDNA Reverse Transcription kit and MultiScribe ${ }^{\circledR}$ enzyme (Life Technologies).

For semi-quantitative Real-Time PCR (qPCR), TaqMan ${ }^{\circledR}$ assays (Life Technologies, Foster City, CA, USA) were used according to the manufacturer's recommendation using cDNA (diluted 1:5) as template. The specific probes and TaqMan ${ }^{\circledR}$ Gene Expression Assays IDs used were Clock (Rn00573120_m1), Bmal1 (Rn00577590_m1), Per1 (Rn01325256_m1), Per2 (Rn01427704_m1), Per3 (Rn00709499_m1), Cry1 (Rn01503063_m1), Cry2 (Rn00591457_m1) Rev-erbo (Rn01460662_m1), and Ror $\alpha$ (Rn01173769_m1) genes. Each PCR reaction was performed in duplicate. Water, instead of cDNA, was used as a negative control. Housekeeping genes, GAPDH (Rn99999916_s1), and ACTB (Rn00667869_m1), mRNA expression were analyzed for each cDNA sample. For each sample, the threshold cycle (Ct) was determined and normalized to the average of the two housekeeping genes $(\Delta \mathrm{Ct}=\mathrm{Ct}$ Unknown $-\mathrm{Ct}$ Housekeeping genes). The determination of gene transcript levels in each sample was obtained by the $2^{-\Delta \Delta C t}$ method (Livak and Schmittgen, 2001). The median value obtained to each sample of tissues from animals submitted to different dietary pattern was compared with the median value obtained from control rats decapitated at ZT3 (0900 h).

\section{Statistical Analysis}

Quantitative variables were expressed as mean and standard error $(\mathrm{X} \pm \mathrm{SEM})$. Differences among morning, afternoon, and night values in the same feeding schedule or differences among rats of different groups at the same time were analyzed by nonparametric analysis of variance of Kruskal-Wallis with Dunn's post-test. Analyses were performed using the GraphPad Prism 5.0 (GraphPad, San Diego, CA). Statistical significance was considered at $P<0.05$.

\section{RESULTS}

\section{Body Weight and Food Intake}

All groups presented similar body weight at the beginning of the experiment. After 21 days, decreased body weight $(P<0.01)$ was observed in RF-n $(274.5 \pm 59.3 \mathrm{~g})$ and RF-d $(250.0 \pm 56.0 \mathrm{~g})$ groups compared with CG $(387.0 \pm 49.1 \mathrm{~g})$ and DF groups (379.5 $\pm 35.7 \mathrm{~g}$ ); no difference was observed between RF-n and RF$\mathrm{d}$ groups as well as between CG and DF groups (Figure 1). Similarly, daily food intake (g) and consequently lower caloric intake were observed $(p<0.0001)$ in RF-n $(15.2 \pm 3.0)$ and RF-d $(14.3 \pm 2.6)$ groups compared with CG $(30.7 \pm 3.8)$ and DF (25.0 \pm 2.8 ) groups; no difference was observed between RF-n and RF$\mathrm{d}$ groups as well as between CG and DF groups. Of note, even after normalization of food intake to body weight, RF-n and RF-d groups still presented smaller ingestion than CG and DF groups.

\section{Plasma Corticosterone Levels}

Figure 2 shows the plasma corticosterone levels $(\mu \mathrm{g} / \mathrm{dl})$ in $\mathrm{CG}$, RF-d, RF-n, and DF groups at ZT3, ZT11, and ZT17. CG presented higher corticosterone levels at ZT11 (14.1 $\pm 8.0 ; P<$ $0.01)$ and ZT17 $(12.9 \pm 6.2 ; P<0.01)$ compared with ZT3 (1.0 $\pm 0.6)$, with no difference between ZT11 and ZT17. The RF-n group showed higher corticosterone levels at ZT11 (20.7 \pm 7.6 , $P<0.01)$ compared with ZT3 $(3.6 \pm 2.6)$ and ZT17 (3.5 \pm 2.6$)$ with no difference between ZT3 and ZT17. On the other hand, RF-d group showed an inverted daily pattern of corticosterone secretion compared with CG and RF-n groups with higher levels at ZT3 (22.7 \pm 6.2$)$ compared with ZT11 (10.6 \pm 5.7) and ZT17 (5.6 $\pm 3.3 ; P=0.0002)$ with no difference between ZT11 and ZT17. The DF group showed higher corticosterone levels at ZT11 $(11.6 \pm 4.0, P<0.01)$ compared with ZT3 $(2.9 \pm 1.6)$ and ZT17 $(7.3 \pm 3.3)$ with no difference either between ZT3 and ZT17 or between ZT11 and ZT17.

\section{Gene Expression}

The expression of clock genes in the SCN of CG, RF-n, RF$\mathrm{d}$, and DF groups at ZT3, ZT11, and ZT17 are presented in Figure 3. Differences among morning, afternoon, and night values in the same feeding schedule showed no difference in Rev-erb $\alpha$ expression among ZT3, ZT11, and ZT17 in any group. In $C G$, no differences were observed in the mRNA expression of Clock, Bmal1, Per1, Per3, Cry1, Cry2, and Ror $\alpha$ among ZT3, ZT11, and ZT17. In DF group, there were no differences in

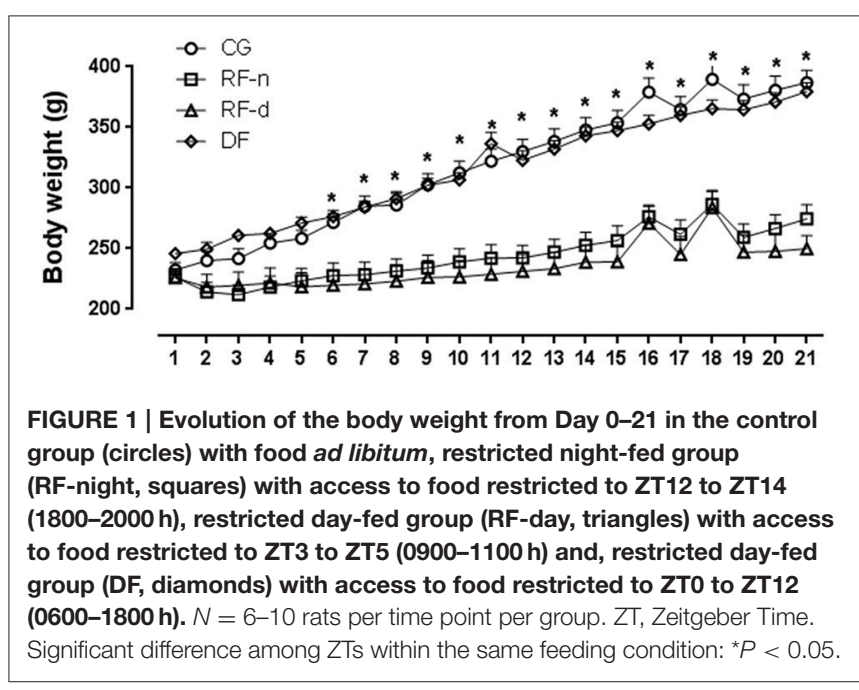



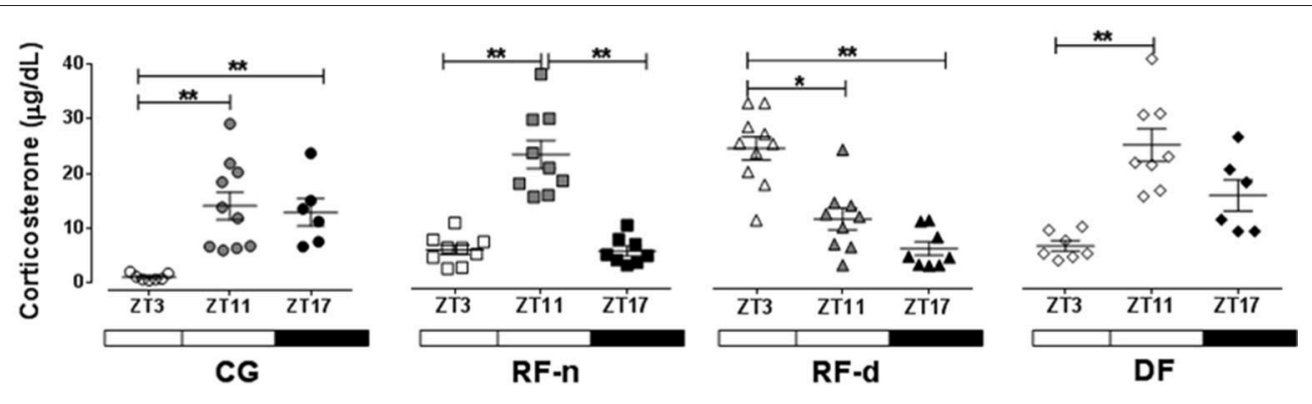

FIGURE 2 | Plasma corticosterone $(\mu \mathrm{g} / \mathrm{dl})$ in the control group (circles) with food ad libitum, restricted night-fed group (RF-night, squares) with access to food restricted to ZT12 to ZT14 (1800-2000 h), restricted day-fed group (RF-day, triangles) with access to food restricted to ZT3-ZT5 (0900-1100 h) and, restricted day-fed group (DF, diamonds) with access to food restricted to ZT0 to ZT12 (0600-1800 h) at ZT3, ZT11, and, ZT17 (black symbols), corresponding to $900, \mathbf{1 7 0 0}$, and $\mathbf{2 3 0 0} \mathrm{h}$; respectively. $N=6-10$ rats per time point per group. ZT, Zeitgeber Time. Significant difference among ZTs within the same feeding condition: ${ }^{\star} P<0.05,{ }^{\star \star} P<0.01$.

the expression of Per3 and Ror $\alpha$ in any ZT, while higher gene expression were observed for Clock at ZT3 compared with ZT11 $(P=0.02)$, for Bmal1 at ZT17 compared with ZT11 $(P=0.01)$, for Cry1, and Cry2 at ZT17 compared with ZT3 $(P=0.03$ and $P=0.02$, respectively), and for Per1 at ZT11 compared with ZT3 $(P=0.02)$. Regarding Per2, the highest expression was observed at ZT11 and the lowest at ZT17 in all groups $(P<$ 0.01). The expression of Clock, Perl, and Per3 genes did not show differences at ZT3, ZT11, and ZT17 in CG; however, in RF-d and RF-n groups, these genes presented higher expression in the morning and in the afternoon $(P<0.01)$. Compared with CG and RF-n groups, in which food access occurred without dissociation with the usual pattern of rat nocturnal activity, higher expression of Bmall was observed at ZT11 $(P=0.05)$ in the RF-d group, while $\operatorname{Cry1}(P<0.01), \operatorname{Cry} 2(P=0.01)$, and Rora at ZT3 and ZT11 $(P<0.01)$.

The expression of clock genes in the PVN of CG, RF-n, RF-d, and DF groups at ZT3, ZT11, and ZT17 are presented in Figure 4. Regarding differences among morning, afternoon, and night values in the same feeding schedule, we observed no differences in the expression of Clock, Bmal1, and Cryl genes at ZT3, ZT11, and ZT17 in any studied group. In the CG, higher Per1 expression was observed in the afternoon (ZT11) and at night (ZT17) $(P<0.01)$, while higher expression of Per2, Per3, and Ror $\alpha(P<0.01)$ were observed at night $(Z T 17)$. No different Rev-erb $\alpha$ expression was observed among the three different ZT points. In the RF-n group, the pattern of expression of Per2 $(P$ $<0.01)$, Per3 $(P=0.04)$, and Ror $(P<0.01)$ genes was similar to CG, with higher expression at night (ZT17), while Per1 and Cry2 diurnal variation observed in the CG was abolished in this group. In the RF-d group, there was no difference in the expression of the studied genes among ZT3, ZT11, and ZT17, with exception of Rev-erbo, which had higher expression at night (ZT17) $(P=$ 0.03). DF group showed higher expression of Ror $\alpha$ and Rev-erba at ZT3 compared with ZT17 $(P=0.02)$.

The expression of clock genes in the ARC of CG, RF-n, RF$\mathrm{d}$, and DF groups at ZT3, ZT11, and ZT17 are presented in Figure 5. No difference in Bmal1 expression was observed among ZT3, ZT11, and ZT17 in any group. In the CG, Cry1 expression was higher $(P=0.02)$ in the morning (ZT3), while Clock, Per1,
Per2, Per3, Cry2, Rev-erb $\alpha$, and Ror $\alpha(P<0.01)$ showed higher expression at night (ZT17). Compared with CG, RF-n and RF-d groups showed similar pattern of expression of Clock $(P<0.01$ and $P=0.04)$, Per3 $(P<0.01$ and $P<0.01), C r y 2(P<0.01$ and $P<0.01)$, and $\operatorname{Ror} \alpha(P<0.01$ and $P<0.01)$, while the pattern of expression of Per2 and Cry1 was lost. RF-n also had higher Per1 expression at ZT17 $(P<0.01)$, while RF-d exhibited higher Per1 expression at morning (ZT3) and at night (ZT17) $(P<$ 0.01). RF-d group maintained the pattern of Rev-erb $\alpha$ expression observed in CG group, while RF-n lost this pattern. DF group presented higher expression of Cry1 at ZT17 than at ZT3 and ZT11 $(P<0.01)$.

\section{The Feeding Restriction Schedules and the Modulation of Temporal Relationship of Clock Gene Expression with Corticosterone Secretion}

In the SCN of control animals, the higher Per2 expression was concomitant with the higher corticosterone secretion while no relationship was observed regarding Clock, Bmall, Per1, Per3, Cry1, Cry2, Rev-erb $\alpha$, and Ror $\alpha$ genes. In the RF-n group, besides Per2, the expression of Clock, Per1, and Per3 genes also exhibited higher expression coinciding with higher corticosterone secretion. The same pattern was observed for Per1 and Per3 in RF-d group, in which there was also a delay of the higher expression of Clock, Bmal1, Per2, Cry1, Cry2, and Ror $\alpha$ compared with the higher corticosterone secretion. On the other hand, in DF group the most interesting finding was the anticipatory higher expression of Clock and Bmal1 regarding the corticosterone secretion.

In the PVN of control animals, the higher expression of Perl, Per2, Per3, Cry2, and Ror $\alpha$ were concomitant with the higher corticosterone secretion, while no relationship was observed regarding Clock, Bmal1, Cry1, and Rev-erb $\alpha$ genes. In the RFn, the higher expression of Per2, Per3, and Ror $\alpha$ was delayed concerning the corticosterone secretion, while there was no relationship regarding the expression of Clock, Bmall, Perl, Cry1, Cry2, and Rev-erbo genes. On the other hand, in the RF-d and DF groups, the majority of the studied genes lost 


\section{Suprachiasmatic nucleus mRNA levels}
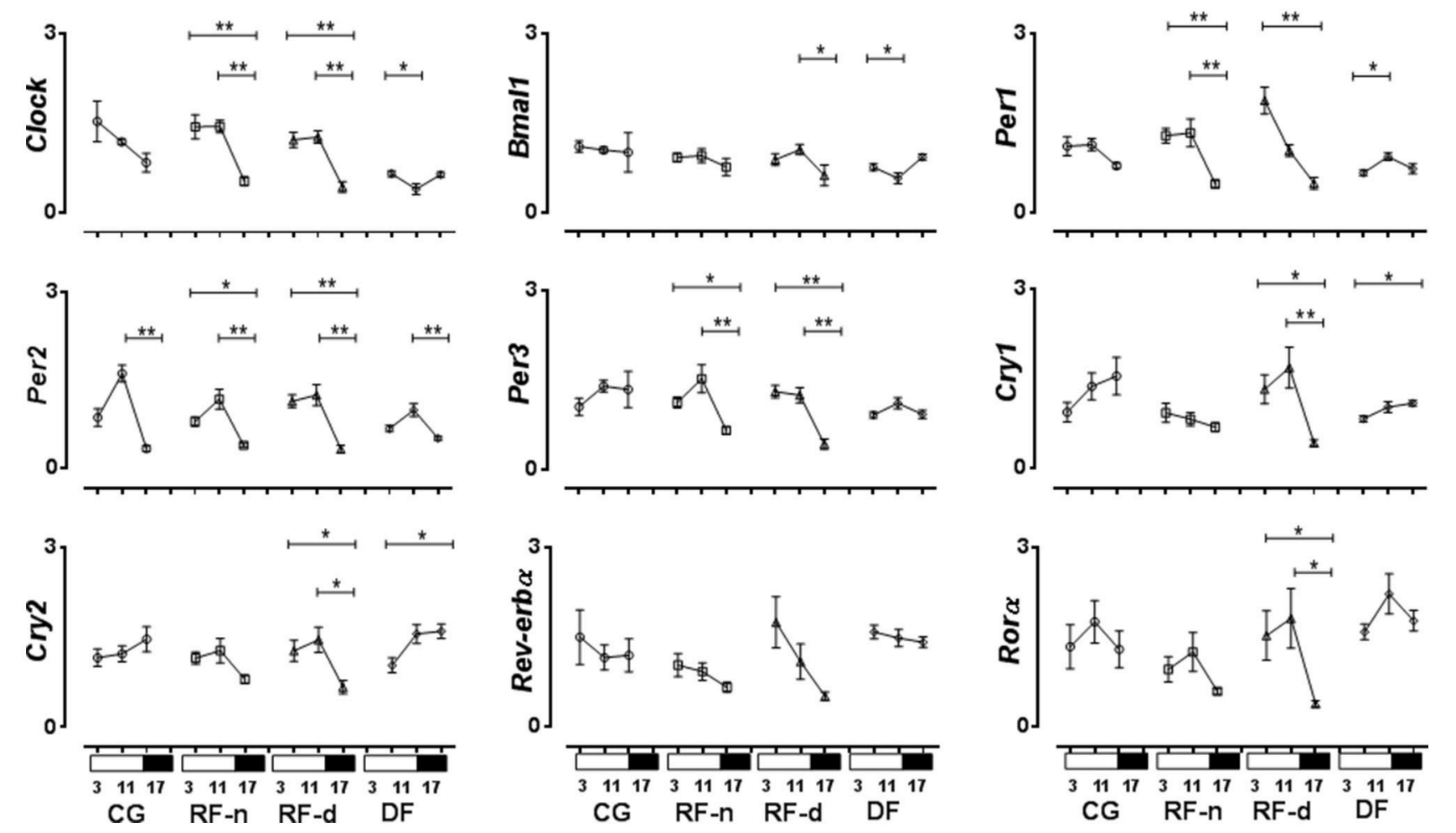

FIGURE 3 | Relative expression of clock genes in Suphrachiasmatic nucleus (SCN) in the control group, with food ad libitum; restricted night-fed group (RF-night), with access to food restricted to ZT12-ZT14 (1800-2000 h); restricted day-fed group (RF-day), with access to food restricted to ZT3-ZT5 (0900-1100 h); and day-fed group (DF), with access to food restricted to ZT0-ZT12 (0600-1800 h) at ZT3, ZT11, and ZT17, corresponding to $\mathbf{0 9 0 0}, \mathbf{1 7 0 0}$, and $\mathbf{2 3 0 0} \mathbf{h}$; respectively. $N=6-10$ rats per time point per group. ZT, Zeitgeber Time. Significant difference among ZTs within the same feeding condition: ${ }^{\star} P<0.05,{ }^{* \star} P<0.01$.

their relationship with corticosterone secretion compared with the pattern observed in control and RF-n groups. Of note, in DF group, the higher expression of Ror $\alpha$ and Rev-erb $\alpha$ was anticipatory concerning corticosterone secretion.

In the ARC of control animals, while the higher expression of Clock, Per1, Per2, Per3, Cry2, Rev-erb $\alpha$, and Ror $\alpha$ was coincident, the Cry1 higher expression was anticipatory in relation to corticosterone secretion. No relationship was observed regarding Bmall gene. On the other hand, in the RF-n and RF-d groups, there was a delay of the higher expression of Clock, Per1, Per3, Cry2, Rev-erb $\alpha$, and Ror $\alpha$ compared with corticosterone secretion. No relationship was observed concerning Bmal1, Cry1, and Per2 in RF-n group and Rev-erb $\alpha$ in RF-d group, respectively. Of note, in DF group, most of the genes lost the pattern of expression, also missing any relationship with corticosterone secretion.

\section{DISCUSSION}

In the present study, rats submitted to three different schedules of food restriction changed the diurnal pattern of Per1, Per2, and
Per3 expression in the SCN and in the extra-SCN oscillatorsPVN and ARC nuclei-suggesting that non-photic cues can modulate the expression of clock genes, but not in a uniform way, throughout the hypothalamic nuclei. Furthermore, the corticosterone anticipatory peak was verified irrespective to the food timing access, except in the DF group. Altogether our data confirm that restricted feeding schedules can be an entrainment cue for glucocorticoid circadian variation.

The initial body weight of rats was similar in all groups, but at the end of the experiment, RF-d and RF-n groups showed lower weight as well as lower daily food intake than control and DF groups, similarly to studies using food restriction but with different duration of food access (Honma et al., 1983; Stephan and Becker, 1989; Stephan, 2002). In our study, the time of feeding in RF-d and RF-n groups was restricted by $2 \mathrm{~h}$ of food access leading to about $50 \%$ calorie intake restriction when compared with controls, suggesting that body weight could be determined primarily by the amount of energy intake and not by the time of feeding. Indeed, control and DF groups showed similar body weight. Arble et al. (2009) showed that mice fed during the 12-h light phase gained even more weight than mice fed on an equivalent amount of calories during the 12-h dark 


\section{Paraventricular nucleus mRNA levels}
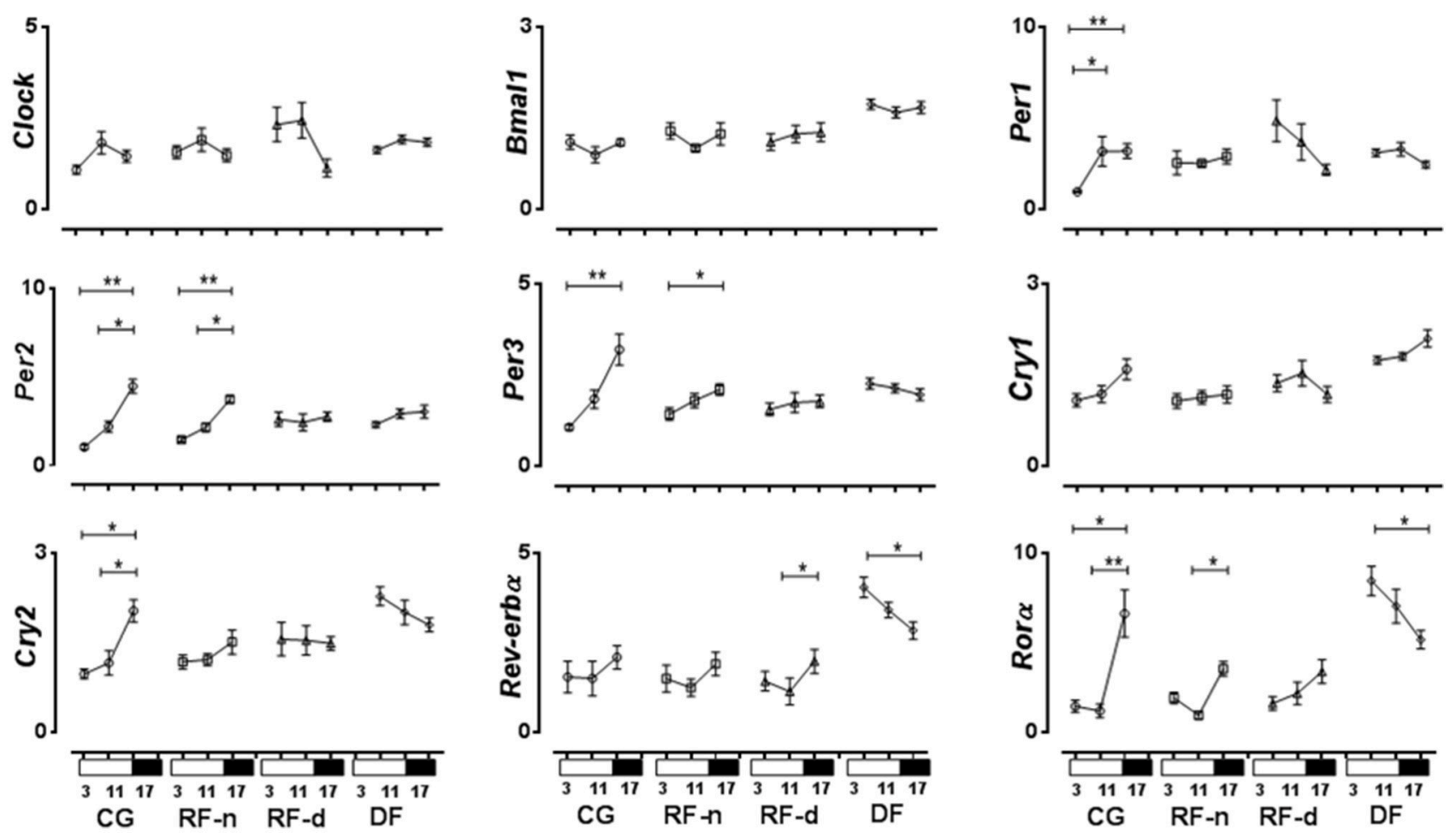

FIGURE 4 | Relative expression of clock genes in Paraventricular nucleus (PVN) in the control group, with food ad libitum; restricted night-fed group (RF-night), with access to food restricted to ZT12 to ZT14 (1800-2000 h); restricted day-fed group (RF-day), with access to food restricted to ZT3 to ZT5 (0900-1100 h); and day-fed group (DF), with access to food restricted to ZT0 to ZT12 (0600-1800 h) at ZT3, ZT11, and ZT17, corresponding to 0900, 1700, and 2300 h; respectively. $N=6-10$ rats per time point per group. ZT, Zeitgeber Time. Significant difference among ZTs within the same feeding condition: ${ }^{\star} P<0.05,{ }^{\star \star} P<0.01$

phase (Arble et al., 2009). Of note, in that study, differently from our study, mice were fed with high-fat diet during 6 weeks. Altogether, these data point out that a longer extent of daytime feeding would be necessary to achieve higher body weight.

Change in the daily eating pattern is considered a powerful Zeitgeber for the diurnal rhythm of glucocorticoids (Krieger, 1974; Leal and Moreira, 1996; Girotti et al., 2009). Higher corticosterone concentrations were observed in the control and RF-n groups at ZT11 than at ZT3, coincident with the onset of the nocturnal activity period of rats (Le Minh et al., 2001). On the other hand, RF-d group, which was allowed to eat only during $2 \mathrm{~h}$ in the morning, showed higher concentrations of corticosterone at ZT3 than at ZT11, inverting the rat corticosterone circadian pattern, as previously described (Krieger, 1974; Moreira and Krieger, 1982; Leal et al., 1995; Leal and Moreira, 1996). Of note, in the RF-n group, in which food access was restricted but occurred without dissociation with the pattern of rat nocturnal activity, we observed an entrainment of corticosterone peak coincident with food availability. Furthermore, the ZT3 and ZT11 time points allowed us to observe the well known anticipatory corticosterone peak before food availability during the light phase of the light/dark cycle (Oliveira et al., 1993; Le Minh et al., 2001). This finding was not observed in the DF group, which presented higher corticosterone levels at ZT11 as control and RF-n groups. Our data are in agreement with previous reports showing that anticipatory corticosterone peak did not happen when food availability occurs during longer intervals of the day (Honma et al., 1983; Belda et al., 2005). Probably, in this situation the photic cue continues as the main Zeitgeber.

In the SCN, all groups of restricted feeding schedules exhibited different patterns of the expression of Clock and Perl genes when compared to the control group, while the Per3 gene expression was only modified in the RF-d and RF-n groups, characterized by an intense food deprivation (food availability restricted by $2 \mathrm{~h}$ ). The expression of Bmal1, Cry1, and Cry 2 was only modified in the RF-d and DF groups, which food access occurred in dissociation with the pattern of rat nocturnal activity, presenting higher expression in the morning, and early evening. In contrast, a higher expression of Per2 at ZT11 than at ZT17 was observed in all groups, thus the expression of this gene was 


\section{Arcuate nucleus mRNA levels}
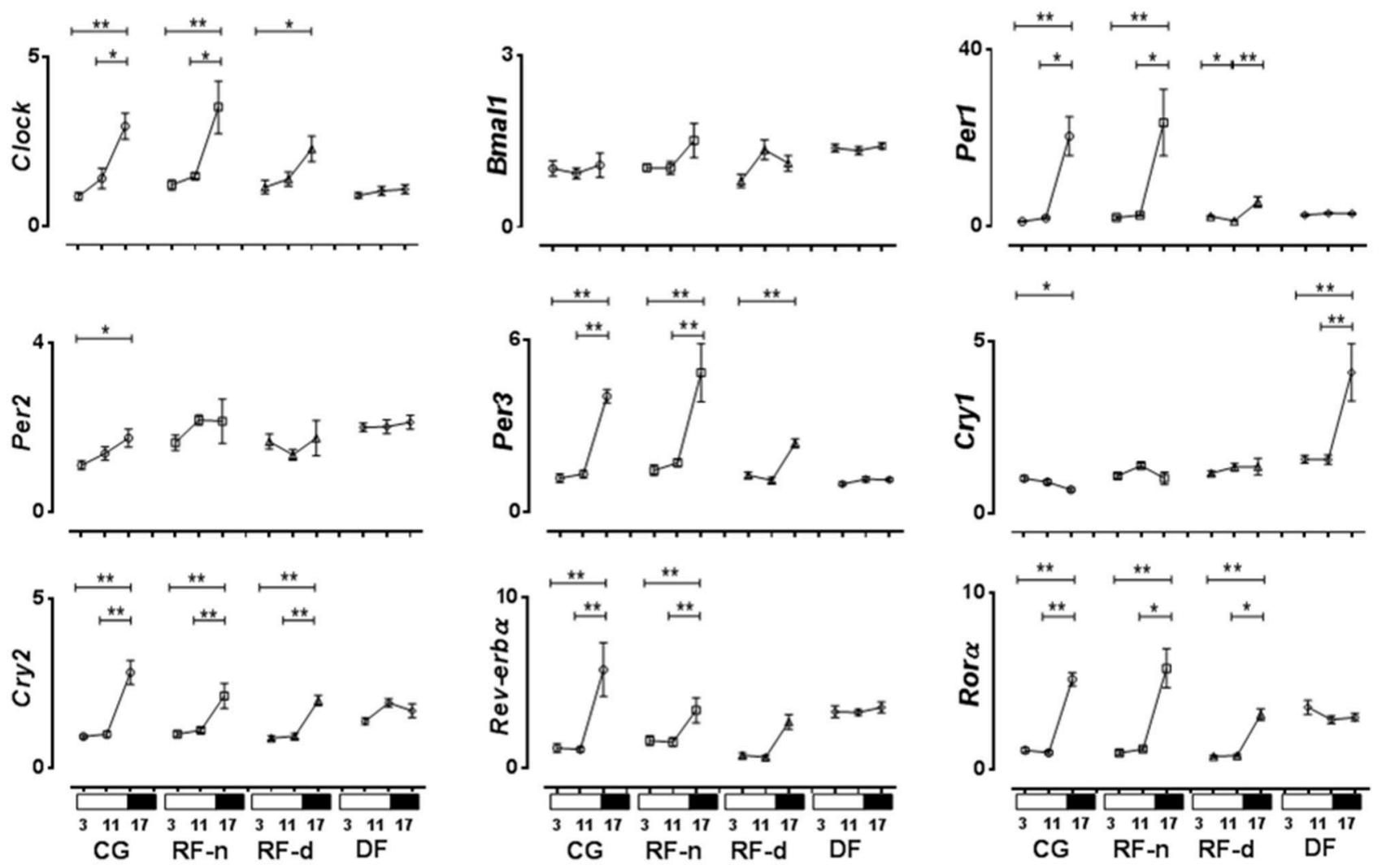

FIGURE 5 | Relative expression of clock genes in Arcuate nucleus (ARC) in the control group, with food ad libitum; restricted night-fed group (RF-night), with access to food restricted to ZT12-ZT14 (1800-2000 h); restricted day-fed group (RF-day), with access to food restricted to ZT3-ZT5 (0900-1100 h); and day-fed group (DF), with access to food restricted to ZT0-ZT12 (0600-1800 h) at ZT3, ZT11, and ZT17, corresponding to 0900, 1700, and $\mathbf{2 3 0 0}$ h; respectively. $N=6-10$ rats per time point per group. ZT, Zeitgeber Time. Significant difference among ZTs within the same feeding condition: ${ }^{\star} P<0.05,{ }^{\star \star} P<0.01$

unchanged by variable food schedule. Our data demonstrated, in agreement with Caldelas et al. (2005) and Minana-Solis et al. (2009) but in contrast to others (Damiola et al., 2000; Hara et al., 2001; Wakamatsu et al., 2001; Verwey et al., 2007) that SCN is also affected by food entrainment. This controversial data can be explained mainly because of the period in which rats were food entrained in the different protocols, as well as by the duration of daily food access, which varied from $2 \mathrm{~h}$, similar to our study, as long as $12 \mathrm{~h}$ as established by Damiola et al. (2000). Thus, time of the day as well as the duration of daily food access may modulate the SCN response, as previously suggested by Minana-Solis et al. (2009). Therefore, feeding cycle can be considered the dominant Zeitgeber for the clock gene expression not only in the peripheral but also in the central pacemakers.

We were not able to detect daily variations in the expression of clock genes in the SCN of the control group, except for Per2. Our protocol explored three time points only, which could be a possible limitation to properly study variations in circadian rhythm but it is still informative to understand the role of restricted feeding on the expression of clock genes in hypothalamic nuclei. However, in the PVN and ARC, higher expressions of Per 2 , Per 3 , and Cry 2 were observed synchronically at ZT17 in the dark period, whereas the other clock genes phased differently. In addition, different food schedules changed the expression of some clock genes in the SCN, PVN, and ARC, compared with CG. Thus, our data demonstrated that under ad libitum food access or under food restriction there are different phases in the clock gene expression between the SCN and extra-SCN nuclei as PVN and ARC hypothalamic nuclei.

Data on ARC and in other energy balance and feeding behavior related areas have shown that dietary restriction induces or increases the amplitude of the daily rhythms of Per1 and Per2 genes and their proteins (Mieda et al., 2006; Verwey et al., 2007; Angeles-Castellanos et al., 2008; Guilding et al., 2009). In addition, c-fos, Per1, Per2, and Bmal1 rhythms were in antiphase with the respective SCN genes in the PVN in rats under food restriction, suggesting that extra-SCN neuronal clocks can be, but not always, expressed in antiphase from the SCN (Damiola et al., 
2000). Another study also showed that the daily food restriction did not lead to a uniform timing effect in clock gene expression in the different hypothalamic nuclei (Minana-Solis et al., 2009). Our data expand these findings since we studied a larger number of clock genes and three different food restriction schedules. Indeed, RF-n, RF-d, and DF groups also showed differential effects on the expression of clock genes, inducing phase alteration in some cases or keeping them unaffected in others. Of note, daily restricted feeding can produce food-entrainable oscillations in the cerebral cortex, hippocampus, striatum, pyriform cortex, and PVN even in SCN-lesioned animals (Wakamatsu et al., 2001). Thus, clock genes in extra-SCN oscillators do not respond to feeding schedules in a uniform manner, suggesting a tissuespecific regulation (Feillet et al., 2008; Minana-Solis et al., 2009).

Our data regarding the modulation of feeding restriction schedules on temporal relationship between clock gene expression and corticosterone secretion show that the most important changes were observed in RF-d and DF groups, in which conditions the eating pattern was not coincident with the onset of the nocturnal activity period, suggesting that a disruption in feeding cues may cause dissociation between gene expression and corticosterone secretion. This misalignment can explain night eating syndrome observed in humans, which is characterized by increased food consumption late in the day, in the evening, and in the night and has been linked to obesity and increased risk of metabolic syndrome (Nader et al., 2010).

In conclusion, our data show that feeding restriction schedules induce changes in the body weight, in the corticosterone circadian variation, and in the expression of the clock genes in hypothalamic nuclei, suggesting the ability of animals to predict, anticipate, and respond to food availability. The pattern of clock gene expression in response to RF-n, RF-d, and DF schedules was not affected uniformly, suggesting that the master oscillator in SCN as well as PVN and ARC, areas involved in energy homeostasis and homeostatic aspect of feeding, are regulated in a tissue-specific manner in response to feeding restriction, a non-photic cue, in order to entrain clock gene system.

\section{REFERENCES}

Angeles-Castellanos, M., Salgado-Delgado, R., Rodriguez, K., Buijs, R. M., and Escobar, C. (2008). Expectancy for food or expectancy for chocolate reveals timing systems for metabolism and reward. Neuroscience 155, 297-307. doi: 10.1016/j.neuroscience.2008.06.001

Arble, D. M., Bass, J., Laposky, A. D., Vitaterna, M. H., and Turek, F. W. (2009). Circadian timing of food intake contributes to weight gain. Obesity 17, 2100-2102. doi: 10.1038/oby.2009.264

Bass, J., and Takahashi, J. S. (2010). Circadian integration of metabolism and energetics. Science 330, 1349-1354. doi: 10.1126/science.1195027

Belda, X., Ons, S., Carrasco, J., and Armario, A. (2005). The effects of chronic food restriction on hypothalamic-pituitary-adrenal activity depend on morning versus evening availability of food. Pharmacol. Biochem. Behav. 81, 41-46. doi: 10.1016/j.pbb.2005.02.009

Buijs, R. M., Van Eden, C. G., Goncharuk, V. D., and Kalsbeek, A. (2003). The biological clock tunes the organs of the body: timing by

\section{AUTHOR CONTRIBUTIONS}

LD: Conception and design of research, performed experiments, analyzed data, interpreted results of experiments, prepared figures, drafted manuscript, edited, and revised manuscript, approved final version of manuscript. SR: Performed experiments, interpreted results of experiments, prepared figures, revised manuscript and approved final version of manuscript. AB: Performed experiments, analyzed data and interpreted results of experiments. FC: Performed experiments, analyzed data and interpreted results of experiments. CM: Performed experiments, analyzed data and interpreted results of experiments, revised manuscript and approved final version of manuscript. EU: Conception and design of research, performed experiments and interpreted results of experiments. JA: Conception and design of research, revised manuscript, approved final version of manuscript. LE: Conception and design of research, revised manuscript, approved final version of manuscript. PE: Conception and design of research, revised manuscript, approved final version of manuscript. AM: Conception and design of research, analyzed data, interpreted results of experiments, edited and revised manuscript, approved final version of manuscript. MC: Conception and design of research, analyzed data, interpreted results of experiments, prepared figures, drafted manuscript, edited and revised manuscript, approved final version of manuscript. I certify that all authors had a substantial contribution to the manuscript.

\section{FUNDING}

National Counsel of Technological and Scientific DevelopmentCNPq, Coordination for the Improvement of Higher Level Personnel-CAPES, Sao Paulo Research Foundation-FAPESP (Process numbers: 2007/58365-3, 2013/09799-1).

\section{ACKNOWLEDGMENTS}

We thank Rogerio Zuliani, Jose Roberto Silva, Maria Valci dos Santos, and Rubens Fernando de Melo for their excellent technical assistance.

hormones and the autonomic nervous system. J. Endocrinol. 177, 17-26. doi: $10.1677 /$ joe.0.1770017

Caldelas, I., Feillet, C. A., Dardente, H., Eclancher, F., Malan, A., Gourmelen, S., et al. (2005). Timed hypocaloric feeding and melatonin synchronize the suprachiasmatic clockwork in rats, but with opposite timing of behavioral output. Eur. J. Neurosci. 22, 921-929. doi: 10.1111/j.1460-9568.2005.04284.x

Castro, M., Figueiredo, F., and Moreira, A. C. (1995). Time-course of hypothalamic $\mathrm{CRH}$ and pituitary ACTH contents, and pituitary responsiveness to $\mathrm{CRH}$ stimulation after bilateral adrenalectomy. Horm. Metab. Res. 27, 10-15. doi: 10.1055/s-2007-979897

Challet, E. (2007). [Clock genes, circadian rhythms and food intake]. Pathol. Biol. 55, 176-177. doi: 10.1016/j.patbio.2006.12.005

Dallman, M. F., Engeland, W. C., Rose, J. C., Wilkinson, C. W., Shinsako, J., and Siedenburg, F. (1978). Nycthemeral rhythm in adrenal responsiveness to ACTH. Am. J. Physiol. 235, R210-R218.

Dallman, M. F., Strack, A. M., Akana, S. F., Bradbury, M. J., Hanson, E. S., Scribner, K. A., et al. (1993). Feast and famine: critical role of glucocorticoids 
with insulin in daily energy flow. Front. Neuroendocrinol. 14, 303-347. doi: 10.1006/frne.1993.1010

Damiola, F., Le Minh, N., Preitner, N., Kornmann, B., Fleury-Olela, F., and Schibler, U. (2000). Restricted feeding uncouples circadian oscillators in peripheral tissues from the central pacemaker in the suprachiasmatic nucleus. Genes Dev. 14, 2950-2961. doi: 10.1101/gad.183500

Fahrenkrug, J., Hannibal, J., and Georg, B. (2008). Diurnal rhythmicity of the canonical clock genes Per1, Per2 and Bmal1 in the rat adrenal gland is unaltered after hypophysectomy. J. Neuroendocrinol. 20, 323-329. doi: 10.1111/j.1365-2826.2008.01651.x

Feillet, C. A., Mendoza, J., Albrecht, U., Pévet, P., and Challet, E. (2008). Forebrain oscillators ticking with different clock hands. Mol. Cell. Neurosci. 37, 209-221. doi: 10.1016/j.mcn.2007.09.010

Girotti, M., Weinberg, M. S., and Spencer, R. L. (2009). Diurnal expression of functional and clock-related genes throughout the rat HPA axis: system-wide shifts in response to a restricted feeding schedule. Am. J. Physiol. Endocrinol. Metab. 296, E888-E897. doi: 10.1152/ajpendo.90946.2008

Green, C. B., Takahashi, J. S., and Bass, J. (2008). The meter of metabolism. Cell 134, 728-742. doi: 10.1016/j.cell.2008.08.022

Guilding, C., Hughes, A. T., Brown, T. M., Namvar, S., and Piggins, H. D. (2009). A riot of rhythms: neuronal and glial circadian oscillators in the mediobasal hypothalamus. Mol. Brain 2:28. doi: 10.1186/1756-6606-2-28

Hara, R., Wan, K., Wakamatsu, H., Aida, R., Moriya, T., Akiyama, M., et al. (2001). Restricted feeding entrains liver clock without participation of the suprachiasmatic nucleus. Genes Cells 6, 269-278. doi: 10.1046/j.1365-2443. 2001.00419.x

Honma, K., Von Goetz, C., and Aschoff, J. (1983). Effects of restricted daily feeding on freerunning circadian rhythms in rats. Physiol. Behav. 30, 905-913. doi: 10.1016/0031-9384(83)90256-1

Ishida, A., Mutoh, T., Ueyama, T., Bando, H., Masubuchi, S., Nakahara, D., et al. (2005). Light activates the adrenal gland: timing of gene expression and glucocorticoid release. Cell Metab. 2, 297-307. doi: 10.1016/j.cmet.2005.09.009

Jang, H., Lee, G., Kong, J., Choi, G., Park, Y. J., and Kim, J. B. (2012). Feeding period restriction alters the expression of peripheral circadian rhythm genes without changing body weight in mice. PLoS ONE 7:e49993. doi: 10.1371/journal.pone.0049993

Kalsbeek, A., Palm, I. F., La Fleur, S. E., Scheer, F. A., Perreau-Lenz, S., Ruiter, M., et al. (2006). SCN outputs and the hypothalamic balance of life. J. Biol. Rhythms 21, 458-469. doi: 10.1177/0748730406293854

Krieger, D. T. (1974). Food and water restriction shifts corticosterone, temperature, activity and brain amine periodicity. Endocrinology 95, 1195-1201. doi: 10.1210/endo-95-5-1195

Krieger, D. T., Hauser, H., and Krey, L. C. (1977). Suprachiasmatic nuclear lesions do not abolish food-shifted circadian adrenal and temperature rhythmicity. Science 197, 398-399. doi: 10.1126/science.877566

Laguna-Abreu, M. T., Koenigkam-Santos, M., Colleta, A. M., Elias, P. C., Moreira, A. C., Antunes-Rodrigues, J., et al. (2005). Time course of vasopressin and oxytocin secretion after stress in adrenalectomized rats. Horm. Metab. Res. 37, 84-88. doi: 10.1055/s-2005-861159

Lamia, K. A., Sachdeva, U. M., Ditacchio, L., Williams, E. C., Alvarez, J. G., Egan, D. F., et al. (2009). AMPK regulates the circadian clock by cryptochrome phosphorylation and degradation. Science 326, 437-440. doi: 10.1126/science. 1172156

Leal, A. M., Forsling, M. L., and Moreira, A. C. (1995). Diurnal variation of the pituitary-adrenal and AVP responses to stress in rats under food restriction. Life Sci. 56, 191-198. doi: 10.1016/0024-3205(94)00434-T

Leal, A. M., and Moreira, A. C. (1996). Feeding and the diurnal variation of the hypothalamic-pituitary-adrenal axis and its responses to $\mathrm{CRH}$ and ACTH in rats. Neuroendocrinology 64, 14-19. doi: 10.1159/000127092

Le Minh, N., Damiola, F., Tronche, F., Schütz, G., and Schibler, U. (2001). Glucocorticoid hormones inhibit food-induced phase-shifting of peripheral circadian oscillators. EMBO J. 20, 7128-7136. doi: 10.1093/emboj/20.24.7128

Livak, K. J., and Schmittgen, T. D. (2001). Analysis of relative gene expression data using real-time quantitative PCR and the $2^{-\Delta \Delta C T}$ method. Methods 25, 402-408. doi: 10.1006/meth.2001.1262

Lowrey, P. L., and Takahashi, J. S. (2004). Mammalian circadian biology: elucidating genome-wide levels of temporal organization. Annu. Rev. Genomics Hum. Genet. 5, 407-441. doi: 10.1146/annurev.genom.5.061903.175925

Mieda, M., Williams, S. C., Richardson, J. A., Tanaka, K., and Yanagisawa, M. (2006). The dorsomedial hypothalamic nucleus as a putative food-entrainable circadian pacemaker. Proc. Natl. Acad. Sci. U.S.A. 103, 12150-12155 doi: 10.1073/pnas.0604189103

Minana-Solis, M. C., Angeles-Castellanos, M., Feillet, C., Pevet, P., Challet, E., and Escobar, C. (2009). Differential effects of a restricted feeding schedule on clockgene expression in the hypothalamus of the rat. Chronobiol. Int. 26, 808-820. doi: 10.1080/07420520903044240

Moreira, A. C., and Krieger, D. T. (1982). The effects of subdiaphragmatic vagotomy on circadian corticosterone rhythmicity in rats with continuous or restricted food access. Physiol. Behav. 28, 787-790. doi: 10.1016/ 0031-9384(82)90194-9

Nader, N., Chrousos, G. P., and Kino, T. (2010). Interactions of the circadian CLOCK system and the HPA axis. Trends Endocrinol. Metab. 21, 277-286. doi: 10.1016/j.tem.2009.12.011

Nakahata, Y., Sahar, S., Astarita, G., Kaluzova, M., and Sassone-Corsi, P. (2009). Circadian control of the $\mathrm{NAD}^{+}$salvage pathway by CLOCK-SIRT1. Science 324, 654-657. doi: 10.1126/science. 1170803

Oliveira, M. H., Antunes-Rodrigues, J., Leal, A. M., Elias, L. L., and Moreira, A. C. (1993). Circadian variations of plasma atrial natriuretic peptide and corticosterone in rats with continuous or restricted access to food. Life Sci. 53, 1795-1801. doi: 10.1016/0024-3205(93)90487-N

Paxinos, G.,A. C. W. (1997). The Rat Brain in Stereotaxic Cordinates. London: Elsevier Inc.

Reppert, S. M., and Weaver, D. R. (2001). Molecular analysis of mammalian circadian rhythms. Annu. Rev. Physiol. 63, 647-676. doi: 10.1146/ annurev.physiol.63.1.647

Schwartz, M. W., Woods, S. C., Porte, D. Jr., Seeley, R. J., and Baskin, D. G. (2000). Central nervous system control of food intake. Nature 404, 661-671. doi: 10. $1038 / 35007534$

Stephan, F. K. (2002). The "other" circadian system: food as a Zeitgeber. J. Biol. Rhythms 17, 284-292. doi: 10.1177/074873002129002591

Stephan, F. K., and Becker, G. (1989). Entrainment of anticipatory activity to various durations of food access. Physiol. Behav. 46, 731-741. doi: 10.1016/0031-9384(89)90359-4

Stephan, F. K., Swann, J. M., and Sisk, C. L. (1979). Entrainment of circadian rhythms by feeding schedules in rats with suprachiasmatic lesions. Behav. Neural Biol. 25, 545-554. doi: 10.1016/S0163-1047(79)90332-7

Stokkan, K. A., Yamazaki, S., Tei, H., Sakaki, Y., and Menaker, M. (2001). Entrainment of the circadian clock in the liver by feeding. Science 291, 490-493. doi: 10.1126/science.291.5503.490

Takahashi, J. S., Hong, H. K., Ko, C. H., and Mcdearmon, E. L. (2008). The genetics of mammalian circadian order and disorder: implications for physiology and disease. Nat. Rev. Genet. 9, 764-775. doi: 10.1038/ $\operatorname{nrg} 2430$

Uchoa, E. T., Silva, L. E., de Castro, M., Antunes-Rodrigues, J., and Elias, L. L. (2012). Glucocorticoids are required for meal-induced changes in the expression of hypothalamic neuropeptides. Neuropeptides 46, 119-124. doi: 10.1016/j.npep.2012.02.002

Verwey, M., Khoja, Z., Stewart, J., and Amir, S. (2007). Differential regulation of the expression of Period2 protein in the limbic forebrain and dorsomedial hypothalamus by daily limited access to highly palatable food in food-deprived and free-fed rats. Neuroscience 147, 277-285. doi: 10.1016/j.neuroscience. 2007.04 .044

Wakamatsu, H., Yoshinobu, Y., Aida, R., Moriya, T., Akiyama, M., and Shibata, S. (2001). Restricted-feeding-induced anticipatory activity rhythm is associated with a phase-shift of the expression of mPer1 and mPer 2 mRNA in the cerebral cortex and hippocampus but not in the suprachiasmatic nucleus of mice. Eur. J. Neurosci. 13, 1190-1196. doi: 10.1046/j.0953-816x.2001. 01483.x

Conflict of Interest Statement: The authors declare that the research was conducted in the absence of any commercial or financial relationships that could be construed as a potential conflict of interest.

Copyright (C) 2016 De Araujo, Roa, Bueno, Coeli-Lacchini, Martins, Uchoa, AntunesRodrigues, Elias, Elias, Moreira and De Castro. This is an open-access article distributed under the terms of the Creative Commons Attribution License (CC BY). The use, distribution or reproduction in other forums is permitted, provided the original author(s) or licensor are credited and that the original publication in this journal is cited, in accordance with accepted academic practice. No use, distribution or reproduction is permitted which does not comply with these terms. 